\title{
Building an Evidence Base for Integration of Social Care Into Health Care: Our Collective Path Ahead
}

\author{
Alicia J. Coben, MD, MSc, FAAFP',2,3 \\ Emilia H. De Marchis, MD, MAS \\ 'Center of Innovation in Long Term Services and Supports, VA Providence Healthcare System, Providence, Rhode Island \\ ${ }^{2}$ Departments of Family Medicine and Health Services, Policy, and Practice, Brown University, Providence, Rhode Island \\ ${ }^{3}$ Department of Family Medicine, University of Michigan, Ann Arbor, Michigan \\ ${ }^{4}$ Department of Family \& Community Medicine, University of California, San Francisco, California
}

Ann Fam Med 2021;19:290-292. https://doi.org/10.1370/afm.2720.

A s adverse social determinants of health are increasingly recognized for their role in perpetuating health inequities and poor health outcomes, there are growing efforts to integrate social care (ie, activities to identify, assist with, and adjust for social risk factors) into health care..$^{1-5}$ Numerous professional societies have called for screening and intervening on patients' social risks. ${ }^{6-10}$ The COVID-19 pandemic has increased the urgency of social care as many patients face new or intensified socioeconomic hardship. ${ }^{11-15}$ Amidst accelerating social care integration efforts, collaboration among researchers, policy makers, payers, and health care systems is needed as the drive to implement outpaces the evidence.

This issue of Annals of Family Medicine includes 3 articles highlighting both how far we have come in advancing the integration of social and medical care, and how much work lies ahead. In their qualitative case study of Michigan federally qualified health centers (FQHCs), Greenwood-Ericksen et al examine the implementation of social risk screening and drivers of variation in social care activities. ${ }^{16}$ In their special report, Hoeft et al translate lessons learned from behavioral health integration to the social care realm. ${ }^{17}$ And finally, in a narrative piece, Fessler et al poignantly reflect on the importance of human connection, and how stepping away from formal training

Conflicts of interest: authors report none.

\section{CORRESPONDING AUTHOR}

Alicia Cohen

830 Chalkstone Ave

Providence, RI 02908

alicia_cohen@brown.edu into community volunteering when medical school clerkships were halted due to COVID-19 enabled a reconnection with why they went into medicine. ${ }^{18}$

Taken together, these 3 articles serve as a timely call to action, reminding readers of the work still needed to meet patients' needs. This work includes improved training and education for all members of the clinical care team around social risk and social care activities, as well as best-practice guidelines, evidencebased interventions, and sustainable funding streams. Commitment to patients and social care integration starts with critically appraising all levels of training and education. Fessler et al speak to how medical training can distance students from their humanity by distilling medically and socially complex patients down to a few "key" descriptors, and how these practices often implicitly blame patients for adverse circumstances. ${ }^{18}$ Both Hoeft et al and Greenwood-Ericksen et al discuss the role of interdisciplinary team-based care in social care integration, and the importance of context-appropriate adaptation. Hoeft et al examine how embracing adaptation as a core implementation strategy has been essential to scaling and disseminating behavioral health integration across clinical settings. ${ }^{17}$ Although the social care integration evidence base is more nascent, an example of such "real world" adaptation is Greenwood-Ericksen et al's finding that community health workers played a critical and often evolving role in FQHC integration efforts. ${ }^{16}$

It is crucial to remember that screening for social risks is not the end goal, as acknowledged by both Hoeft et $\mathrm{a}^{17}$ and Greenwood-Ericksen et al ${ }^{16}$ Screening is a necessary input to enable health care team identification of patients who may be experiencing social risks. Yet similar to the patient health questionnaire 2 (PHQ-2), screening for social risks is not 
diagnostic, and when not followed-up, has the potential for harm. ${ }^{19,20}$ Screening may not always result in patient disclosure of their social risks or interest in assistance, ${ }^{21-24}$ and resources may be limited and vary by setting (not dissimilar to behavioral health). But this does not mean that screening-when done sensitively and appropriately-is not worth pursuing. Conversations around patients' social contexts can build relationships ${ }_{1}^{25}$ guide treatment and follow-up that is accessible and acceptable to patients, ${ }^{26}$ and can empower patients to be active agents in their own care. ${ }^{16}$ Furthermore, social risk data can aid advocacy and policy efforts to expand community-based resources, efforts to address health inequities, and population health-level interventions more broadly. ${ }^{26}$ Without adequate preparation to integrate social care activities into practice, however, health care teams may be ill-equipped to handle implementation challenges.

These articles further highlight the importance of the sustainability of social care activities. An obstacle to social care integration is the funding stream itself, often relying on temporary grants from funders with their own priorities and agendas, which-as GreenwoodEricksen et al found-can drive local implementation decisions. ${ }^{16}$ Both greater flexibility in use of Center for Medicare \& Medicaid Services dollars ${ }^{27-29}$ and the new 2021 Evaluation \& Management (E/M) coding guidelines for social determinants ${ }^{30}$ may facilitate more consistent funding for social care activities. Such funding mechanisms will be critical to support meaningful and sustainable social care integration into medical care.

Central to building the case for sustainable funding streams is a robust evidence base around implementation best practices and outcomes. Learning collaboratives_-such as the Texas Managed Care Organization Social Determinants of Health Learning Collaborative $^{31}$ — and online repositories — such as the Social Interventions Research \& Evaluation Network's Evidence \& Resource Library ${ }^{32}$ — can assist in these efforts. Hybrid design implementation studies can enable simultaneous evaluation of both efficacy and implementation. ${ }^{33}$ While high-quality evidence is necessary to guide the field and inform future guidelines, ${ }^{34,35}$ Hoeft et al remind us that we may not have to reinvent the wheel. ${ }^{17}$

Hoeft et al identify specific next steps to advance and scale social care integration, including developing and prioritizing a set of core social risk measures that are appropriate to patients and across multiple contexts. ${ }^{17}$ Consistent and shared coding and metrics can aid population health efforts, increase the ease of social risk documentation, and improve monitoring and actionability of social risk information. ${ }^{36}$ Efforts to facilitate social determinants data capture such as the Gravity Project are actively working toward that goal. ${ }^{37}$
While there is urgency to implement social care activities now, we must also ensure we are learning from on-the-ground efforts and building the evidence base to inform uptake and sustainability of future social care integration. The 3 articles included in this issue are a step in that direction, ${ }^{16-18}$ each highlighting areas for continued progress. The path ahead requires working together and sharing learnings to advance our common goal of achieving health equity and wellness-for patients and the health care workforce alike.

To read or post commentaries in response to this article, go to https://www.AnnFamMed.org/content/19/4/290/tab-e-letters.

Key words: social determinants of health; social environment; social work; medical care integration; healthcare disparities

Submitted May 25, 2021; accepted May 26, 2021.

Funding support: A.J.C.'s time was supported by VA Health Services Research \& Development grant CDA 20-037.

Acknowledgments: The authors would like to thank Michele Heisler and Jason Buxbaum for their thoughtful review of an earlier draft of this editorial.

\section{References}

1. Kangovi S, Mitra N, Grande D, Long JA, Asch DA. Evidence-Based community health worker program addresses unmet social needs and generates positive return on investment. Health Aff (Millwood). 2020;39(2):207-213.

2. Horwitz LI, Chang C, Arcilla HN, Knickman JR. Quantifying health systems' investment in social determinants of health, by sector, 2017-19. Health Aff (Millwood). 2020;39(2):192-198.

3. Murray GF, Rodriguez HP, Lewis VA. Upstream with a small paddle: how ACOs are working against the current to meet patients' social needs. Health Aff (Millwood). 2020;39(2):199-206.

4. Gold R, Bunce A, Cowburn S, et al. Adoption of social determinants of health EHR tools by community health centers. Ann Fam Med. 2018;16(5):399-407.

5. The EveryONE project: screening tools and resources to advance health equity. American Academy of Family Physicians. Updated 2021. Accessed May 18, 2021. https://www.aafp.org/patient-care/ social-determinants-of-health/ejveryone-project/tools.html\#patients

6. Czapp P, Kovach K. Poverty and health - the family medicine perspective (position paper). American Academy of Family Physicians. Published 2015. https://www.aafp.org/about/policies/all/povertyhealth.html

7. Council on Community Pediatrics. Poverty and child health in the United States. Pediatrics. 2016;137(4):e20160339. 10.1542/ peds.2016-0339.

8. Council on Community Pediatrics; Committee on Nutrition. Promoting food security for all children. Pediatrics. 2015;136(5): e1431-e1438. 10.1542/peds.2015-3301.

9. Daniel H, Bornstein SS, Kane GC; Health and Public Policy Committee of the American College of Physicians. Addressing social determinants to improve patient care and promote health equity: an American College of Physicians position paper. Ann Intern Med. 2018;168(8):577-578.

10. Alcaraz KI, Wiedt TL, Daniels EC, Yabroff KR, Guerra CE, Wender RC. Understanding and addressing social determinants to advance cancer health equity in the United States: a blueprint for practice, research, and policy. CA Cancer J Clin. 2020;70(1):31-46.

11. Abrams EM, Szefler SJ. COVID-19 and the impact of social determinants of health. Lancet Respir Med. 2020;8(7):659-661. 
12. COVID-19 collection: social determinants of health and COVID-19. 2020. Published 2020. Accessed Oct 12, 2020. https://www. Ann FamMed.org/content/covid-19-collection-social-determinants-healthand-covid-19

13. Gottlieb LM, Pantell MS, Solomon LS. The National Academy of Medicine social care framework and COVID-19 care innovations. J Gen Intern Med. 2021;36(5):1411-1414.

14. Benfer E, Wiley L. Health justice strategies to combat COVID19: protecting vulnerable communities during a pandemic. Health Affairs blog. Mar 19, 2020. https://www.healthaffairs.org/ do/10.1377/hblog20200319.757883/full/

15. Peretz PJ, Islam N, Matiz LA. Community health workers and COVID-19-addressing social determinants of health in times of crisis and beyond. N Eng J Med. 2020;383:e108.

16. Greenwood-Ericksen M, Dejonckheere M, Syed F, Choudhury N, Cohen AJ, Tipirneni R. Implementation of health-related social needs screening at Michigan health centers: a qualitative study. Ann Fam Med. 2021;19(4):310-317.

17. Hoeft TJ, Hessler D, Francis D, Gottlieb LM. Applying lessons from behavioral health integration to social care integration in primary care. Ann Fam Med. 2021;19(4):356-361.

18. Fessler MM, Bishop RA, Jabour SM, Vasudevan A. Sandwiches, 6 feet apart: reflections on community (and medical school) during COVID-19. Ann Fam Med. 2021;19(4):368-370.

19. Garg A, Boynton-Jarrett R, Dworkin PH. Avoiding the unintended consequences of screening for social determinants of health. JAMA. 2016;316(8):813-814.

20. Gottlieb L, Fichtenberg C, Adler N. Screening for social determinants of health. JAMA. 2016;316(23):2552.

21. De Marchis EH, Alderwick H, Gottlieb LM. Do patients want help addressing social risks? J Am Board Fam Med. 2020;33(2):170-175.

22. De Marchis EH, Hessler D, Fichtenberg C, et al. Assessment of social risk factors and interest in receiving health care-based social assistance among adult patients and adult caregivers of pediatric patients. JAMA Netw Open. 2020;3(10):e2021201.

23. Steiner JF, Bellows J, Banegas MP, Gottlieb LM. Interventions to address basic resource needs in Kaiser Permanente: a care continuum and an outcomes wheel. Perm J. 2018;22:18-130.

24. DeVoe JE. When and how do we need permission to help patients address social risk? J Am Board Fam Med. 2020;33(2):176-178.

25. Byhoff E, De Marchis EH, Hessler D, et al. Part II: a qualitative study of social risk screening acceptability in patients and caregivers. Am J Prev Med. 2019;57(6)(Suppl 1):S38-S46.

26. National Academies of Sciences, Engineering, and Medicine. Integrating Social Care Into the Delivery of Health Care: Moving Upstream to Improve the Nation's Health. The National Academies Press; 2019. https://doi.org/10.17226/25467.
27. Garg A, Homer CJ, Dworkin PH. Addressing social determinants of health: challenges and opportunities in a value-based model. Pediatrics. 2019;143(4):e20182355.

28. Skopec L, Ramos C, Aarons J. Are Medicare Advantage plans using new supplemental benefit flexibility to address enrollees' healthrelated social needs? Urban Institute. Published Sep 2019. https:// www.urban.org/research/publication/are-medicare-advantage-plansusing-new-supplemental-benefit-flexibility-address-enrollees-healthrelated-social-needs-0

29. Gottlieb L, Razon N, \& Aboelata N. How do community health centers pay for social care programs? SIREN. Published 2019. Accessed May 19, 2021. https://sirenetwork.ucsf.edu/tools-resources/ resources/how-do-safety-net-clinics-pay-social-care-programs

30. Gottlieb LM, DeSilvey SC. New clinical coding guidelines account for patients' social risk: we should do more to ensure they advance health care quality and equity. Health Affairs blog. Dec 3, 2020. https://www.healthaffairs.org/do/10.1377/hblog20201201.150443/ full/

31. Texas managed care organization social determinants of health learning collaborative. Center for Health Care Strategies. Updated 2021. Accessed May 19, 2021. https://www.chcs.org/project/texasmanaged-care-organization-social-determinants-of-health-learningcollaborative/

32. Evidence \& resource library. Social Interventions Research \& Evaluation Network. Updated 2021. Accessed May 19, 2021. https:// sirenetwork.ucsf.edu/tools/evidence-library

33. Curran GM, Bauer M, Mittman B, Pyne JM, Stetler C. Effectivenessimplementation hybrid designs: combining elements of clinical effectiveness and implementation research to enhance public health impact. Med Care. 2012;50(3):217-226.

34. Fichtenberg CM, Alley DE, Mistry KB. Improving social needs intervention research: key questions for advancing the field. Am J Prev Med. 2019;57(6)(Suppl 1):S47-S54.

35. Krist AH, Davidson KW, Ngo-Metzger Q, Mills J. Social determinants as a preventive service: U.S. Preventive Services Task Force methods considerations for research. Am J Prev Med. 2019;57(6) (Suppl 1):S6-S12.

36. Pantell MS, Adler-Milstein J, Wang MD, Prather AA, Adler NE, Gottlieb LM. A call for social informatics. J Am Med Inform Assoc. 2020; 27(11):1798-1801.

37. The Gravity Project. Confluence. Updated May 18, 2021. Accessed May 19, 2021. https://confluence.hl7.org/display/GRAV/The+ Gravity+Project

\section{CORRECTIONS}

Ann Fam Med 2021;19:292. https://doi.org/10.1370/afm.2692.

In: Ebell MH, Bentivegna M, Hulme C. Cancer-Specific mortality, all-cause mortality, and overdiagnosis in lung cancer screening trials: a meta-analysis. Ann Fam Med. 2020;18(6):545-552, the x-axis in Figure 1 was labeled incorrectly and the scale was incorrect. The author regrets the error and the figure has been corrected online; therefore the online version of record differs from the print publication.

In Newton WP, Baxley E, Magill MK. Learning from COVID-19: system blindness to primary care. Ann Fam Med. $2021 ; 19(3): 282-284$, there was a typo on p. 282. The number of primary care office visits annually is over 4,000,000, not 400,00 as originally published. The online version has been corrected ${ }_{i}$ therefore it differs from the print publication.

In both cases, the authors regret the errors. 